\title{
Estrutura do dossel e acúmulo de forragem de Brachiaria brizantha cultivar Xaraés em resposta a estratégias de pastejo
}

\author{
Bruno Carneiro e Pedreira(1), Carlos Guilherme Silveira Pedreira ${ }^{(1)}$ e Sila Carneiro da Silva ${ }^{(1)}$
}

(1)Escola Superior de Agricultura Luiz de Queiroz, Av. Pádua Dias, no 11, CEP 13418-970 Piracicaba, SP. E-mail: pedreira@esalq.usp.br,
cgspedre@esalq.usp.br, scdsilva@esalq.usp.br

Resumo - O objetivo deste trabalho foi avaliar o desempenho agronômico do capim-xaraés [Brachiaria brizantha (A. Rich.) Stapf. cv. Xaraés] em resposta a três estratégias de pastejo rotacionado: uma baseada no calendário (pastejo a cada 28 dias) e duas em função da interceptação luminosa (IL) pelo dossel (pastejo iniciado a $95 \%$ ou $100 \%$ de IL). No tratamento $95 \%$ de IL, a altura média pré-pastejo foi $29,5 \mathrm{~cm}$; no $100 \%$ de IL, foi $41,6 \mathrm{~cm}$ e no 28 dias, $34,2 \mathrm{~cm}$. A altura média pós-pastejo foi 14,6 cm em todos os tratamentos, e correspondeu a um índice de área foliar médio de 0,73 , IL de $42 \%$ e ângulo da folhagem de $65,2^{\circ}$. No pré-pastejo, o ângulo da folhagem não variou com as estratégias de pastejo e correspondeu a um valor médio de $41,6^{\circ}$. A altura do dossel e a IL correspondente ao longo da rebrotação estiveram correlacionadas em todos os tratamentos. O tratamento $100 \%$ de IL resultou em maior intervalo entre pastejos e maior acúmulo de forragem em relação aos tratamentos $95 \%$ de IL e 28 dias de descanso, porém essa maior produção foi alcançada por meio de maiores quantidades acumuladas de colmos e de material morto.

Termos para indexação: interceptação luminosa, IAF, ângulos foliares, pastejo rotacionado.

\section{Sward structure and herbage accumulation in Brachiaria brizantha cultivar Xaraés in response to strategies of grazing}

\begin{abstract}
The objective of this work was to evaluate the agronomic performance of Xaraés palisadegrass [Brachiaria brizantha (A. Rich.) Stapf cv. Xaraés] in response to rotational grazing managements defined by either pre-graze canopy light interception (LI) or calendar days. Mean pre-graze sward height was $29.5 \mathrm{~cm}$ for the $95 \%$ LI pastures, $41.6 \mathrm{~cm}$ for $100 \% \mathrm{LI}$, and $34.2 \mathrm{~cm}$ for the 28 -day schedule. Mean post-graze sward height was $14.6 \mathrm{~cm}$ across treatments, which corresponded to a mean 0.73 leaf area index, $42 \% \mathrm{LI}$ and $65.2^{\circ}$ foliage angle. At pre-graze, foliage angles were not affected by grazing management (mean $=41.6^{\circ}$ ). Sward height and LI were highly correlated across treatments. Grazing at $100 \%$ LI resulted in longer intervals between grazings and higher herbage accumulation than the other two treatments, although this higher accumulation corresponded mainly to large amounts of stem and dead material.
\end{abstract}

Index terms: light interception, LAI, leaf angle, rotational grazing.

\section{Introdução}

O ecossistema pastagem é muito dinâmico, com os mecanismos e processos envolvidos na produção, colheita e transformação da forragem em produto animal atuando de forma integrada e compensatória. Isto dificulta o alcance de resultados líquidos positivos provenientes de ações isoladas em qualquer compartimento do sistema (Silva \& Sbrissia, 2001).

O crescimento das plantas está condicionado primariamente à obtenção de energia proveniente da radiação solar, que deve ser interceptada pela área foliar do dossel e utilizada nos processos fotossintéticos
(Nabinger \& Pontes, 2001). Folhas são o principal constituinte da área foliar fotossinteticamente ativa e eficiente, e são produzidas de acordo com uma programação morfogênica das plantas que sofre influência direta de fatores de meio ambiente, até mesmo da desfolhação (Lemaire \& Chapman, 1996).

A dinâmica de acúmulo de forragem foi descrita por Hodgson (1990) para espécies de clima temperado e, de maneira geral, apresenta uma fase inicial de crescimento lento, seguida de acúmulo acelerado e, finalmente, uma fase na qual as taxas de acúmulo tendem a zero e o dossel se aproxima da máxima produção líquida, que é mantida a partir de então e pode ser 
reduzida em casos de intervalos muito longos entre desfolhações sucessivas. No caso de algumas espécies forrageiras tropicais, especialmente as de crescimento ereto, não se pode deixar de inserir nos componentes do crescimento o alongamento de colmos, que freqüentemente ocorre ainda na fase vegetativa e interfere significativamente na estrutura do dossel e nos equilíbrios dos processos de competição por luz (Silva $\&$ Sbrissia, 2001) afetando o acúmulo de forragem.

$\mathrm{O}$ alongamento de folhas e colmos, assim como o aparecimento e a longevidade das folhas e perfilhos determinam o índice de área foliar (IAF) e as características estruturais do dossel (Chapman \& Lemaire, 1993) que, por sua vez, interferem na forma como a forragem é oferecida aos animais. O estudo das características morfofisiológicas e estruturais das plantas forrageiras é necessário para promover o entendimento da dinâmica de produção de forragem e suas relações dentro de sistemas de produção animal em pastagens.

Estratégias de pastejo afetam as características da planta forrageira, e a utilização de interceptação luminosa como referência de acompanhamento do processo de rebrotação permite que a forragem seja colhida (por corte ou pastejo) sempre numa mesma condição fisiológica. Em contrapartida, métodos tradicionais de uso de estratégias de pastejo baseadas em calendário para colheita de gramíneas tropicais, com períodos fixos e predeterminados de rebrotação, são inflexíveis e generalistas ao extremo. Estudos recentes com base no uso da interceptação de luz como forma de controlar e monitorar o processo de pastejo têm demonstrado resultados promissores, pois sugerem que essa técnica pode contribuir para a otimização da produtividade de sistemas de produção animal em pastagens (Silva, 2004; Carnevalli et al., 2006). Contudo, nenhum estudo comparou o desempenho de plantas forrageiras submetidas a essa estratégia de controle da desfolhação em relação à tradicional, baseada em um intervalo fixo e predeterminado entre desfolhações. Contrastar as estratégias de pastejo baseadas em IL com as baseadas em calendário permitiria evidenciar as divergências entre esses dois métodos de colheita de forragem e fornecer subsídios para ajustes eficazes nas atuais práticas de manejo do pastejo.

O objetivo deste estudo foi avaliar as características morfogênicas e estruturais e a produção de forragem do capim-xaraés submetido a estratégias de pastejo rotacionado.

\section{Material e Métodos}

$\mathrm{O}$ experimento foi conduzido em área experimental do Departamento de Zootecnia da Escola Superior de Agricultura Luiz de Queiroz (Esalq), localizada no Município de Piracicaba, SP, a $580 \mathrm{~m}$ de altitude, $22^{\circ} 42^{\prime} \mathrm{S}$ e $47^{\circ} 30^{\prime} \mathrm{W}$, e com características médias das normais meteorológicas correspondentes a uma precipitação de $1.002 \mathrm{~mm}$ e $23,6^{\circ} \mathrm{C}$ de temperatura média durante o verão (outubro a março). Dados climáticos referentes ao período experimental foram obtidos no posto meteorológico do Departamento de Ciências Exatas da Esalq, distante cerca de $1 \mathrm{~km}$ da área experimental. O solo da área experimental é classificado como Nitossolo Vermelho eutroférrico típico (Embrapa, 1999), sem necessidade de correção.

Foram feitas apenas adubações de produção, totalizando $120 \mathrm{~kg} \mathrm{ha}^{-1}$ de $\mathrm{N}$ e $120 \mathrm{~kg} \mathrm{ha}^{-1}$ de $\mathrm{K}_{2} \mathrm{O}$ nas formas de sulfato de amônio e cloreto de potássio, respectivamente. Para tanto, foram realizadas duas adubações manuais, metade no início da estação chuvosa (23/09/2005), após pastejo de uniformização $(15 \mathrm{~cm})$, e o restante no meio do ciclo, entre os dias 3 e 16 de dezembro de 2005. Essa segunda adubação foi feita na condição pós-pastejo em todos os tratamentos.

Os tratamentos corresponderam a três estratégias de pastejo rotacionado: uma baseada no calendário (pastejo a cada 28 dias) e duas definidas em função da interceptação luminosa (IL) pelo dossel para início do pastejo (95 ou 100\% de IL), com um único resíduo póspastejo de $15 \mathrm{~cm}$ de acordo com a recomendação da Embrapa (Embrapa Acre, 2003) para o capim-xaraés. Os tratamentos foram alocados às unidades experimentais $\left(120 \mathrm{~m}^{2}\right)$ segundo delineamento inteiramente casualizado com três repetições. $O$ pastejo foi feito por novilhas das raças Holandesa (Bos taurus taurus L.) e Nelore (Bos taurus indicus L.) com peso médio de $350 \mathrm{~kg}$. A técnica de "mob-grazing" (Mislevy et al., 1981) foi usada para a realização dos pastejos, empregando-se grupos de animais para desfolhações rápidas (duração de 4 a 20 horas), simulando um cenário de pastejo rotacionado. Cada piquete foi cercado com cerca elétrica para a contenção dos animais durante o pastejo. À medida que os animais pastejavam, medições de altura eram feitas até que o dossel atingisse a meta de resíduo de $15 \mathrm{~cm}$.

Durante os 153 dias do período experimental (22 de setembro de 2005 a 22 de fevereiro de 2006), em cada 
ciclo de pastejo, foram feitas amostragens para quantificação da massa de forragem (MF), pré-pastejo e pós-pastejo, cortando-se, em cada amostragem, a forragem contida no interior de duas molduras retangulares $(0,5 \times 1,0 \mathrm{~m})$ em pontos do piquete, onde a MF era representativa da média (avaliação visual) da área por ocasião da amostragem (Guzman et al., 1992). As amostras de MF foram sempre cortadas a $10 \mathrm{~cm}$ da superfície do solo. Após o corte, as amostras foram levadas ao laboratório e pesadas. De cada amostra, foi tomada uma subamostra de aproximadamente $500 \mathrm{~g}$, colocada em estufa de circulação forçada de ar a $65^{\circ} \mathrm{C}$ até peso constante, para determinação do peso seco.

$\mathrm{O}$ acúmulo de forragem foi calculado por meio da diferença entre a MF no pré-pastejo atual e no póspastejo anterior para cada ciclo de pastejo. Esse valor foi dividido pelo número de dias de acúmulo de cada ciclo de pastejo de cada piquete, gerando-se a taxa média de acúmulo de forragem $\left(\mathrm{kg} \mathrm{ha}^{-1} \mathrm{dia}^{-1} \mathrm{de} \mathrm{MS}\right)$ para cada ciclo de pastejo. Tanto o acúmulo quanto a taxa média diária de acúmulo de forragem foram ponderados para o número e duração dos ciclos de pastejo em cada mês do ano, e médias mensais para essas variáveis foram calculadas, como forma de permitir uma base comum para a comparação dos tratamentos (caracterizados por número de ciclos e intervalo entre pastejos diferentes) ao longo do tempo.

As medições de altura, interceptação luminosa (IL), índice de área foliar (IAF) e ângulo da folhagem (ANG) foram feitas durante todos os ciclos de pastejo, iniciandose imediatamente depois do pastejo, durante a rebrotação a cada sete dias, e imediatamente antes do pastejo seguinte, objetivando caracterizar as variações estruturais da comunidade vegetal. Em cada avaliação, a altura foi medida em 20 pontos representativos da condição média do dossel na unidade experimental, utilizando-se régua e transparência (Fagundes et al., 1999). Em avaliações relativas a IL, IAF e ANG foi utilizado o analisador de dossel LI-COR modelo LAI 2000, cujo funcionamento foi descrito por Welles \& Norman (1991), e permite amostragens rápidas e não destrutivas. Essa técnica combina medidas tomadas com o sensor acima do dossel (Io) com medidas tomadas sob o dossel próximas ao nível do solo (I). A partir dessas medidas, a inversão de um modelo de transferência de luz permite o cálculo do IAF (Welles \& Norman, 1991). Foram tomados 20 pontos representativos da condição média do dossel em cada piquete nas ocasiões de amostragem, na proporção de uma medida acima para cinco medidas abaixo do dossel (nível do solo), sempre utilizando estações entre touceiras. A IL de 100\%, devido à impossibilidade prática de ser alcançada (o aparelho LAI-2000 não registra $100 \%$ de IL), foi considerada como alcançada quando o dossel apresentava valores de IL acima de $97,5 \%$ por dois dias consecutivos.

As características estruturais do dossel foram estudadas de duas formas: levando em consideração as respostas de acordo com as estratégias de manejo ao longo do experimento como um todo, avaliando-se todos os ciclos de pastejo; e levando-se em consideração o primeiro e o último ciclo de pastejo para cada tratamento, independentemente do número de ciclos.

A fim de descrever o acúmulo de forragem durante a rebrotação foram acompanhados dois ciclos de pastejo durante a estação chuvosa. Em cada um desses dois ciclos (outubro/novembro e janeiro/fevereiro, correspondendo à primavera e verão, respectivamente) foram feitas amostragens para caracterização morfológica e quantificação da MF no pós-pastejo e no pré-pastejo e a cada incremento de $5 \mathrm{~cm}$ de altura do dossel durante a rebrotação. Concomitantemente a essa avaliação, foi realizada a avaliação de IL e ANG. No póspastejo, a forragem contida no interior de duas molduras retangulares $(0,33 \times 1,20 \mathrm{~m})$ foi cortada rente ao solo, colhendo a forragem representante do resíduo. Nas ocasiões subsequientes, a cada $5 \mathrm{~cm}$ de incremento até o pré-pastejo, a amostra foi colhida, acima da altura do resíduo de pastejo $(15 \mathrm{~cm})$. A amostra colhida em cada quadrado foi levada ao laboratório para separação manual nos componentes morfológicos folha (lamina foliares), colmo (colmos e bainhas foliares) e material morto, os quais foram posteriormente levados à estufa de circulação forçada de ar a $65^{\circ} \mathrm{C}$ até peso constante.

Os dados foram analisados por meio do procedimento MIXED do software estatístico SAS (SAS Institute, 1989; Littel et al., 1996), específico para casos de medidas repetidas no tempo e em que o tempo é um fator a ser estudado como causa de variação, e a comparação de médias, quando apropriada, foi realizada com nível de probabilidade de $10 \%$, pelo teste de Tukey. Os dados de taxa de acúmulo mensal e estrutura em pós-pastejo e pré-pastejo foram avaliados por meio do procedimento MIXED, utilizando ciclos de pastejo como subparcela repetida no tempo, com o comando "Repeated", que foi usado para modelar a estrutura de co-variâncias entre os ciclos (matriz R), uma vez que as 
medidas foram feitas repetidamente em cada piquete. Dessa maneira, manejo e ciclo de pastejo foram considerados como efeitos fixos para as variáveis estruturais. Quanto à taxa média diária mensal de acúmulo de forragem, foram utilizados manejo e mês do ano como efeitos fixos. Correlações entre as variáveis morfofisiológicas altura, IAF e IL foram determinadas utilizando-se o procedimento CORR do pacote estatístico SAS (SAS Institute, 1989).

\section{Resultados e Discussão}

O intervalo entre pastejos diferente entre os tratamentos resultou em números diferentes de ciclos de pastejo ao final do período experimental. Os piquetes manejados a 95\% de IL foram pastejados mais vezes durante o período experimental que os piquetes manejados a $100 \%$ de IL $(\mathrm{p}=0,0001) . \mathrm{O}$ tratamento baseado no calendário (28 dias) apresentou número de pastejos intermediário aos regimes baseados em IL (Tabela 1).

O tratamento $100 \%$ de IL resultou em maior intervalo entre pastejos (Tabela 1) e, conseqüentemente, maior período de rebrotação, propiciando maior acúmulo $(\mathrm{p}=0,0360)$ de forragem por ciclo de pastejo em relação aos tratamentos 95\% de IL e 28 dias (Tabela 1). As taxas médias diárias de acúmulo de forragem foram afetadas pelas estratégias de pastejo $(\mathrm{p}=0,0061)$, pelos meses ao longo do período experimental $(\mathrm{p}<0,0001)$ e pela interação estratégia de pastejo x mês $(\mathrm{p}=0,0018)$. Os tratamentos $95 \%$ de IL e 28 dias apresentaram taxas

Tabela 1. Número de pastejos realizados, intervalo médio entre pastejos e acúmulo total de forragem durante o período experimental em capim-xaraés, submetido a diferentes estratégias de pastejo rotacionado ${ }^{(1)}$.

\begin{tabular}{lccc}
\hline Estratégia & $\begin{array}{c}\text { Número } \\
\text { de pastejos }\end{array}$ & $\begin{array}{c}\text { Intervalo de } \\
\text { pastejos (dias) }\end{array}$ & $\begin{array}{c}\text { Acúmulo total } \\
\left(\mathrm{kg} \mathrm{ha}^{-1} \mathrm{de} \mathrm{MS}\right)\end{array}$ \\
\hline $95 \% \mathrm{IL}$ & $6 \mathrm{a}$ & $22,0 \mathrm{c}$ & $17.380 \mathrm{~b}$ \\
$100 \% \mathrm{IL}$ & $4 \mathrm{c}$ & $31,7 \mathrm{a}$ & $22.760 \mathrm{a}$ \\
$28 \mathrm{dias}$ & $5 \mathrm{~b}$ & $27,7 \mathrm{~b}$ & $18.040 \mathrm{~b}$ \\
\hline
\end{tabular}

${ }^{(1)}$ Médias na coluna seguidas da mesma letra não diferem entre si pelo teste de Tukey, a $10 \%$ de probabilidade. médias de acúmulo de forragem semelhantes e constantes ao longo do experimento (Tabela 2). De novembro de 2005 a fevereiro de 2006 não houve diferença nas taxas de acúmulo de forragem entre as estratégias de pastejo. Apesar disso, na média, o tratamento $100 \%$ de IL apresentou as maiores taxas de acúmulo, o que pode ser explicado pelo aumento nas taxas de acúmulo de colmo (Silva, 2004), conseqüência do incremento da competição por luz que normalmente ocorre a partir dos $95 \%$ de IL e se torna mais intenso quanto mais longo o intervalo entre pastejos (Figura 1).

Setembro, outubro e dezembro apresentaram as maiores taxas médias de acúmulo de forragem, possivelmente em resposta à adubação nitrogenada e potássica realizada nos pós-pastejos em setembro e dezembro, época de elevada disponibilidade de fatores de crescimento como temperatura e precipitação. Nos meses subseqüentes, quando não houve reposição de nutrientes, via adubação, as taxas de acúmulo foram menores (Tabela 2).

Os valores de IL pré-pastejo foram 95,4 e 98,1\% para os tratamentos 95 e $100 \%$ de IL, respectivamente $(\mathrm{p}=0,0367)$. No tratamento 28 dias, a IL pré-pastejo variou no decorrer do experimento entre 88,1 a $98,2 \%$ de IL, com um valor médio de $94,8 \%$, semelhante ao do tratamento $95 \%$ de IL.

A estratégia de manejo afetou o IAF $(\mathrm{p}=0,0065)$ e a altura do dossel pré-pastejo $(\mathrm{p}=0,0002)$, com maiores valores registrados no tratamento $100 \%$ de IL (Tabela 3). Os tratamentos 95\% de IL e 28 dias, apesar de apresentarem valores médios de IAF semelhantes, apresentaram alturas pré-pastejo diferentes, demonstrando a variabilidade na arquitetura do dossel ocorrida no tratamento baseado no calendário, conseqüência de mudanças na IL ao longo do período experimental. Os ângulos da folhagem não variaram $(p=0,2777)$ com as estratégias de pastejo avaliadas e apresentaram valor médio de $41,6^{\circ}$. Esse valor é consistente com os reportados por Molan (2004) para capim-marandu (Brachiaria brizantha $\mathrm{cv}$. Marandu).

Tabela 2. Taxa média diária mensal de acúmulo de forragem em capim-xaraés, submetido a estratégias de pastejo rotacionado ${ }^{(1)}$.

\begin{tabular}{|c|c|c|c|c|c|c|c|}
\hline \multirow[t]{2}{*}{ Estratégia } & Setembro & Outubro & Novembro & Dezembro & Janeiro & Fevereiro & Média \\
\hline & \multicolumn{7}{|l|}{ - . - . - - } \\
\hline $95 \%$ IL & $130,2 \mathrm{Ab}$ & $129,2 \mathrm{Ab}$ & $122,9 \mathrm{Aa}$ & $136,5 \mathrm{Aa}$ & $117,7 \mathrm{Aa}$ & $90,2 \mathrm{Aa}$ & $121,1 b$ \\
\hline $100 \%$ IL & $236,3 \mathrm{Aa}$ & $221,4 \mathrm{Aa}$ & $150,0 \mathrm{BCa}$ & $184,0 \mathrm{ABa}$ & $153,2 \mathrm{BCa}$ & $95,7 \mathrm{Ca}$ & $173,4 a$ \\
\hline 28 dias & $143,8 \mathrm{Ab}$ & $134,7 \mathrm{Ab}$ & $123,3 \mathrm{Aa}$ & $135,8 \mathrm{Aa}$ & $127,7 \mathrm{Aa}$ & $121,9 \mathrm{Aa}$ & $131,2 \mathrm{~b}$ \\
\hline Média & $170,1 \mathrm{~A}$ & $161,7 \mathrm{~A}$ & 132,1B & $152,1 \mathrm{AB}$ & $132,8 \mathrm{~B}$ & $102,6 \mathrm{C}$ & \\
\hline
\end{tabular}

${ }^{(1)}$ Médias seguidas da mesma letra, minúscula na coluna e maiúscula na linha, não diferem entre si pelo teste de Tukey, a $10 \%$ de probabilidade. 
Na condição pós-pastejo, as características estruturais (IL, altura, IAF e ANG) não variaram com as estratégias de pastejo nem ao longo dos ciclos de pastejo ( $p>0,10)$. A altura pós-pastejo foi, em média, $14,6 \mathrm{~cm}$, com IAF médio de $0,73,42,1 \%$ de IL e ângulo da folhagem de $65,2^{\circ}$. Esses resultados indicam alteração na estrutura do dossel ao longo da rebrotação, caracterizada pelo aumento em altura, IAF e redução do ANG (folhas dispostas mais horizontalmente), fatores determinantes do aumento de IL pelo dossel. Um padrão análogo de resposta foi descrito por Carnevalli et al. (2006) para capim-mombaça (Panicum maximum cv. Mombaça) submetido a estratégias de pastejo rotacionado baseadas nos mesmos critérios de IL utilizados neste estudo.

A IL esteve positivamente associada à altura e ao IAF ao longo da rebrotação quanto a todas as estratégias de pastejo avaliadas. Em alturas acima de $30 \mathrm{~cm}$, valor que correspondeu a 95\% de IL, a dispersão dos dados diminuiu e, a partir desse ponto, os incrementos em altura foram sempre maiores do que os respectivos incrementos em IL. Nesse momento a planta inicia o alongamento de colmos e aumenta o acúmulo de material morto na base do dossel (Figura 1). Essa relação entre IL x IAF e IL x altura do dossel foi descrita em diferentes cultivares de $P$. maximum por Carnevalli (2003), Moreno (2004), Barbosa (2004) e Mello \& Pedreira (2004) de maneira análoga ao reportado em capim-xaraés.

Brougham (1956), em trabalho pioneiro, ao avaliar pastagens consorciadas de azevém perene (Lolium perenne L.), trevo-vermelho (Trifolium pratense L.) e

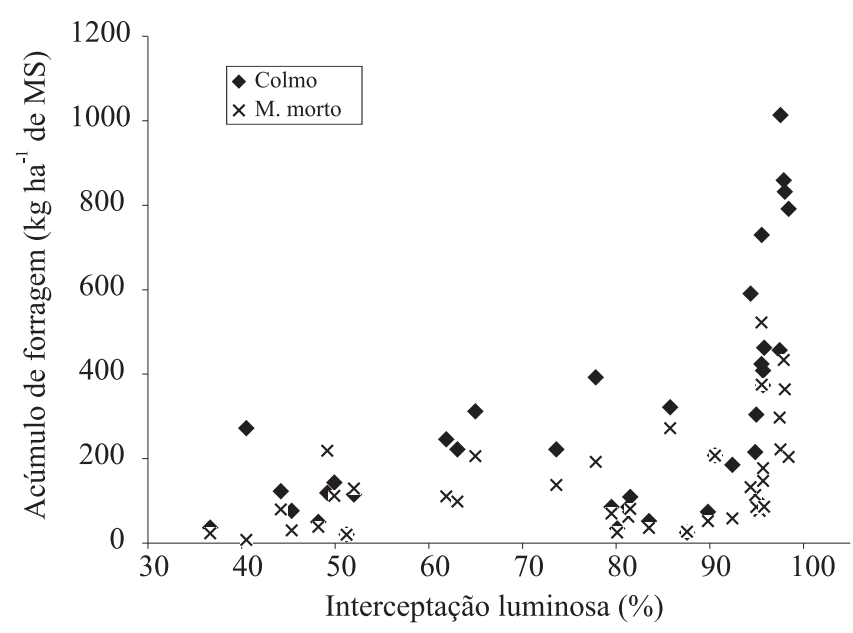

Figura 1. Acúmulo dos componentes colmo e material morto ao longo do período de rebrotação em pastos de capim-xaraés, submetido a estratégias de pastejo rotacionado. trevo-branco (Trifolium repens L.), sob lotação intermitente com três intensidades de desfolhação, descreveu um padrão semelhante de relação entre IL e IAF, mostrando que as taxas de acúmulo estavam relacionadas com a luz interceptada pelo dossel e com a área foliar. Taxas máximas foram mantidas aproximadamente constantes, quando a área foliar do dossel era suficiente para interceptar $95 \%$ da luz incidente (Parsons et al., 1988), assim como neste estudo.

Os resultados deste estudo revelaram, também, associação consistente entre IL e altura do dossel durante todo período experimental independentemente de tratamento $(\mathrm{r}=0,84 ; \mathrm{p}<0,0001)$, sugerindo que a altura pode ser usada como uma ferramenta de manejo para controle e monitoramento do processo de pastejo. Essa mesma relação foi verificada com os valores de IAF $(\mathrm{r}=0,92 ; \mathrm{p}<0,0001)$ que, ao longo do experimento, mostraram-se consistentemente relacionados aos valores de IL em todos os tratamentos. Braga et al. (2006), trabalhando com capim-marandu sob lotação rotacionada, sugeriram que as relações entre IL e altura podem mudar ao longo do tempo e que, ao menos em regimes de desfolhação intermitente, essa associação deveria ser feita de maneira cautelosa, como mostraram Parsons et al. (1988) e Busque \& Herrero (2001). De acordo com Lemaire \& Chapman (1996), essas relações de IL com IAF e com altura do dossel só deveriam ser exploradas quando a pastagem estivesse sendo manejada com a IL como critério para a entrada dos animais, pois as plantas respondem adaptando-se aos impactos da desfolhação, restabelecendo e mantendo um equilíbrio de crescimento quando os recursos são utilizados de maneira balanceada, atingindo um padrão ótimo de crescimento.

Um contraste entre os dosséis pós-pastejo do início da estação (setembro) com os do final do período experimental (fevereiro) revela que os tratamentos alteraram as características estruturais de maneiras

Tabela 3. Valores de interceptação luminosa (IL), altura e índice de área foliar (IAF) pré-pastejo em capim-xaraés, submetido a estratégias de pastejo rotacionado ${ }^{(1)}$.

\begin{tabular}{lccc}
\hline Estratégia & IL & $\begin{array}{c}\text { Altura } \\
(\mathrm{cm})\end{array}$ & IAF \\
\hline $95 \%$ IL & $95,4 \mathrm{~b}$ & $29,5 \mathrm{c}$ & $3,73 \mathrm{~b}$ \\
$100 \% \mathrm{IL}$ & $98,1 \mathrm{a}$ & $41,6 \mathrm{a}$ & $4,70 \mathrm{a}$ \\
28 dias & $94,8 \mathrm{~b}$ & $34,2 \mathrm{~b}$ & $3,70 \mathrm{~b}$ \\
\hline
\end{tabular}

${ }^{(1)}$ Médias na coluna seguidas da mesma letra não diferem entre si pelo teste de Tukey, a $10 \%$ de probabilidade. 
diferentes (Tabela 4). A IL sofreu efeito da interação estratégia de pastejo $\mathrm{x}$ ciclo de pastejo $(\mathrm{p}=0,0791)$, apresentando, no regime de desfolhação menos freqüente (100\% de IL), a maior IL no último ciclo, conseqüência do acúmulo de colmos e material morto (Tabela 5), como resultado do intervalo mais longo entre pastejos. Os ângulos da folhagem pós-pastejo não variaram dentro de tratamentos ao longo da estação e foram, em média, de $68^{\circ}$. A IL e o IAF, dentro de tratamentos, não foram afetados pelos ciclos de pastejo ao longo da estação. Apenas o tratamento $100 \%$ de IL apresentou incremento em IL e IAF do primeiro para o último ciclo (Tabela 4).

De maneira geral, as plantas se tornaram mais eretas, com os valores de ANG pré-pastejo aumentando do primeiro $\left(39^{\circ}\right)$ para o último $\left(43,4^{\circ}\right)$ ciclo, mostrando a plasticidade do capim-xaraés em alterar sua estrutura, de modo a permitir maior iluminação da área foliar existente e sugerindo uma adaptação dessa planta em resposta ao manejo imposto. Isso foi confirmado no tratamento $95 \%$ de IL, o qual manteve estáveis a altura e o IAF, aumentando a quantidade de luz no interior do dossel (Tabela 6). De acordo com Loomis \& Williams

Tabela 4. Interceptação luminosa e índice de área foliar póspastejo em capim-xaraés, submetido a estratégias de pastejo rotacionado, no primeiro (setembro/outubro) e no último (janeiro/fevereiro) ciclo de pastejo ${ }^{(1)}$.

\begin{tabular}{lccccc}
\hline \multirow{2}{*}{ Estratégia } & \multicolumn{2}{c}{ Interceptação luminosa (\%) } & & \multicolumn{2}{c}{ Índice de área foliar } \\
\cline { 2 - 3 } \cline { 5 - 6 } & Primeiro & Último & & Primeiro & Último \\
\hline $95 \%$ IL & $38,7 \mathrm{Aa}$ & $39,3 \mathrm{Aa}$ & & $0,63 \mathrm{Aa}$ & $0,69 \mathrm{Aa}$ \\
$100 \% \mathrm{IL}$ & $38,6 \mathrm{Ba}$ & $52,1 \mathrm{Aa}$ & & $0,64 \mathrm{Ba}$ & $0,94 \mathrm{Aa}$ \\
28 dias & $41,6 \mathrm{Aa}$ & $40,7 \mathrm{Aa}$ & & $0,73 \mathrm{Aa}$ & $0,69 \mathrm{Aa}$ \\
\hline Média & $39,6 \mathrm{~A}$ & $44,0 \mathrm{~A}$ & $0,67 \mathrm{~B}$ & $0,78 \mathrm{~A}$ \\
\hline
\end{tabular}

${ }^{(1)}$ Médias seguidas da mesma letra, minúscula na coluna e maiúscula na linha, não diferem entre si pelo teste de Tukey, a $10 \%$ de probabilidade.

Tabela 5. Massa de colmos pós-pastejo em capim-xaraés, submetido a estratégias de pastejo rotacionado, no primeiro (setembro/outubro) e no último (janeiro/fevereiro) ciclo de pastejo $^{(1)}$.

\begin{tabular}{lccc}
\hline Estratégia & Primeiro & $\begin{array}{c}\text { Último } \\
\end{array}$ & $\ldots \ldots \ldots$ \\
\hline & & Colmo & Média \\
$95 \% \mathrm{IL}$ & $1.100 \mathrm{Bb}$ & $1.410 \mathrm{Ac}$ & $1.260 \mathrm{~b}$ \\
$100 \% \mathrm{IL}$ & $1.540 \mathrm{Ba}$ & $2.220 \mathrm{Aa}$ & $1.880 \mathrm{a}$ \\
$28 \mathrm{dias}$ & $1.670 \mathrm{Aa}$ & $1.850 \mathrm{Ab}$ & $1.760 \mathrm{a}$ \\
\hline Média & $1.440 \mathrm{~B}$ & $1.830 \mathrm{~A}$ & \\
\hline & & Material morto \\
$95 \% \mathrm{IL}$ & $1.780 \mathrm{Aa}$ & $1.490 \mathrm{Aa}$ & \\
$100 \% \mathrm{IL}$ & $1.530 \mathrm{Ba}$ & $2.200 \mathrm{Aa}$ & \\
28 dias & $2.020 \mathrm{Aa}$ & $1.890 \mathrm{Aa}$ & \\
\hline
\end{tabular}

(1)Médias seguidas da mesma letra, minúscula na coluna e maiúscula na linha, não diferem entre si pelo teste de Tukey, a $10 \%$ de probabilidade.
Tabela 6. Interceptação luminosa (IL), altura e índice de área foliar (IAF) pré-pastejo em capim-xaraés, submetido às estratégias de pastejo rotacionado, no primeiro (setembro/outubro) e no último (janeiro/fevereiro) ciclo de pastejo $^{(1)}$.

\begin{tabular}{|c|c|c|c|c|c|c|}
\hline \multirow[t]{2}{*}{ Estratégia } & \multicolumn{2}{|c|}{ IL (\%) } & \multicolumn{2}{|c|}{ Altura $(\mathrm{cm})$} & \multicolumn{2}{|c|}{ IAF } \\
\hline & Primeiro & Último & Primeiro & Último & Primeiro & Último \\
\hline $95 \%$ IL & $96,1 \mathrm{Ab}$ & $95,1 \mathrm{Bb}$ & $29,8 \mathrm{Ab}$ & $28,9 \mathrm{Ac}$ & $3,86 \mathrm{Ac}$ & $3,60 \mathrm{Ab}$ \\
\hline $100 \% \mathrm{IL}$ & $98,4 \mathrm{Aa}$ & $98,1 \mathrm{Aa}$ & $42,0 \mathrm{Aa}$ & $41,6 \mathrm{Aa}$ & $4,89 \mathrm{Aa}$ & $4,71 \mathrm{Aa}$ \\
\hline 28 dias & 97,9Aa & $95,6 \mathrm{Bb}$ & $41,1 \mathrm{Aa}$ & $35,3 \mathrm{Bb}$ & $4,53 \mathrm{Ab}$ & $3,77 \mathrm{Bb}$ \\
\hline Média & $97,5 \mathrm{~A}$ & $96,3 \mathrm{~B}$ & $37,6 \mathrm{~A}$ & $35,3 \mathrm{~B}$ & $4,42 \mathrm{~A}$ & $4,02 \mathrm{~B}$ \\
\hline
\end{tabular}

${ }^{(1)}$ Médias seguidas da mesma letra, minúscula na coluna e maiúscula na linha, não diferem entre si pelo teste de Tukey, a 10\% de probabilidade.

(1969), a maior eficiência de utilização da luz é alcançada quando muitas folhas são iluminadas com modesta quantidade de luz, comparativamente a uma situação de exposição de poucas folhas a sol pleno.

\section{Conclusões}

1. A altura é um parâmetro eficiente e prático para ser utilizado como indicador do nível de interceptação de luz pelo dossel de capim-xaraés sob pastejo rotacionado.

2. A estratégia de pastejo rotacionado baseada em 95\% de IL no pré-pastejo favorece a produção de forragem de maneira eficiente e evita o acúmulo excessivo de colmos e de material morto.

3. O manejo baseado em dias fixos e predeterminados de descanso restringe as possibilidades de ganho em eficiência do sistema de pastejo.

\section{Agradecimentos}

À Fundação de Amparo à Pesquisa do Estado de São Paulo, pelo apoio financeiro.

\section{Referências}

BARBOSA, R.A. Características morfofisiológicas e acúmulo de forragem em capim-tanzânia (Panicum maximum Jacq. cv. Tanzânia) submetido à freqüências e intensidades de pastejo. 2004. 97p. Tese (Doutorado) - Universidade Federal de Viçosa, Viçosa.

BRAGA, G.J.; PEDREIRA, C.G.S.; HERLING, V.R.; LUZ, P.H.C.; LIMA, C.G. Sward structure and herbage yield of rotationally stocked pastures of 'Marandu' palisadegrass [Brachiaria brizantha (A. Rich.) Stapf] as affected by herbage allowance. Scientia Agricola, v.63, p.121-129, 2006.

BROUGHAM, R.W. Effect of intensity of defoliation on regrowth of pasture. Australian Journal of Agricultural Research, v.7, p.377-387, 1956. 
BUSQUE, J.; HERRERO, M. Sward structure and patterns of defoliation of signal grass (Brachiaria decumbens) pastures under different cattle grazing intensities. Tropical Grasslands, v.35, p.193204, 2001.

CARNEVALLI, R.A. Dinâmica da rebrotação de pastos de capimmombaça submetidos a regimes de desfolhação intermitente. 2003. 136p. Tese (Doutorado) - Escola Superior de Agricultura Luiz de Queiroz, Piracicaba.

CARNEVALLI, R.A.; SILVA, S.C. da; BUENO, A.A.O.; UEBELE, M.C.; BUENO, F.O.; SILVA, G.N.; MORAES, J.P. Herbage production and grazing losses in Panicum maximum cv. Mombaça under four grazing managements. Tropical Grasslands, v.40, p.165176, 2006.

CHAPMAN, D.; LEMAIRE, G. Morphogenetic and structural determinants of plant regrowth after defoliation. In: BAKER, M.J. (Ed.). Grasslands for our world. Wellington: SIR Publishing, 1993. p.95-104.

EMBRAPA. Centro Nacional de Pesquisa de Solos (Rio de Janeiro, RJ). Sistema brasileiro de classificação de solos. Rio de Janeiro, 1999. 412p.

EMBRAPAACRE. Sistemas de produção de gado de corte. 2003. Disponível em: <http://sistemasdeproducao.cnptia.embrapa.br/ FontesHTML/BovinoCorte/BovinoCorteAcre/index.htm>. Acesso em: 10 fev. 2005.

FAGUNDES, J.L.; SILVA, S.C. da; PEDREIRA, C.G.S.; SBRISSIA, A.F.; CARNEVALLI, R.A.; CARVALHO, C.A.B.; PINTO, L.F.M. Índice de área foliar, interceptação luminosa e acúmulo de forragem em pastagens de Cynodon spp. sob diferentes intensidades de pastejo. Scientia Agricola, v.56, p.1141-1150, 1999.

GUZMAN, G.A.B.; NASCIMENTO JUNIOR, D.; REGAZZI, A.J.; OBEID, J.A.; QUEIROZ, A.C. Estudo do tamanho e forma ideal da unidade amostral na avaliação da disponibilidade de matéria seca em pastagens. I. Método da máxima curvatura do coeficiente de variação. Revista Brasileira de Zootecnia, v.21, p.396-405, 1992.

HODGSON, J. Grazing management: science into practice. New York: Wiley; Burnt Mill, Harlow, Essex: Longman Scientific and Technical, 1990. 203p.

LEMAIRE, G.; CHAPMAN, D. Tissue fluxes in grazing plant communities. In: HODGSON, J.; ILLIUS, A.W. (Ed.). The ecology and management of grazing systems. Wallingford: $C A B$ International, 1996. p.3-36.

LITTELL, R.C.; MILLIKEN, G.A.; STROUP, W.W.; WOLFINGER, R.D. SAS system for mixed models. Cary: SAS Institute, 1996. 633p.
LOOMIS, R.S.; WILLIAMS, W.A. Productivity and the morphology of crop stands: patterns with leaves. In: EASTIN, J.D.; HASKINS, F.A.; SULLIVAN, C.Y.; VAN BAVEL, C.H.M. (Ed.). Physiological aspects of crop yield. Madison: ASA/CSSA/SSA, 1969. p.27-47.

MELLO, A.C.L.; PEDREIRA, C.G.S. Respostas morfofisiológicas do capim-tanzânia (Panicum maximun cv. Tanzânia) irrigado à intensidade de desfolha sob lotação rotacionada. Revista Brasileira de Zootecnia, v.33, p.282-289, 2004.

MISLEVY, P.; MOTT, G.O.; MARTIN, F.G. Screening perennial forages by mob-grazing technique. In: INTERNATIONAL GRASSLAND CONGRESS, 14., 1981, Lexington. Proceedings. Lexington, 1981. p.516-519.

MOLAN, L.K. Estrutura do dossel, interceptação luminosa e acúmulo de forragem em pastos de capim-marandu submetidos a alturas de pastejo por meio de lotação contínua. 2004. 159p. Dissertação (Mestrado) - Escola Superior de Agricultura Luiz de Queiroz, Piracicaba.

MORENO, L.S.B. Produção de forragem de capins do gênero Panicum e modelagem de respostas produtivas e morfofisiológicas em função de variáveis climáticas. 2004. 86p. Dissertação (Mestrado) - Escola Superior de Agricultura Luiz de Queiroz, Piracicaba.

NABINGER, C.; PONTES, L.S. Morfogênese de plantas forrageiras e estrutura do pasto. In: REUNIÃO ANUAL DA SOCIEDADE BRASILEIRA DE ZOOTECNIA, 38., 2001, Piracicaba. Anais. Piracicaba: SBZ, 2001. p.755-771.

PARSONS, A.J.; JOHNSON, I.R.; HARVEY, A. Use of a model to optimize the interactions between frequency and severity of intermittent defoliation and to provide a fundamental comparison of the continuous and intermittent defoliation of grass. Grass and Forage Science, v.43, p.49-59, 1988.

SAS INSTITUTE (Cary, Estados Unidos). SAS/STAT: user's guide. Version 6. $4^{\text {th }}$ ed. Cary, 1989. v.2. 846p.

SILVA, S.C. da. Understanding the dynamics of herbage accumulation in tropical grass species: the basis for planning efficient grazing management pratices. In: SIMPÓSIO EM ECOFISIOLOGIA DAS PASTAGENS E ECOLOGIA DO PASTEJO, 2., 2004, Curitiba. Anais. Curitiba: UFPR, 2004. 1 CD-ROM.

SILVA, S.C. da; SBRISSIA, A.F. A planta forrageira no sistema de produção. In: SIMPÓSIO SOBRE MANEJO DA PASTAGEM, 17., 2001, Piracicaba. Anais. Piracicaba: Fealq, 2001. p.71-88.

WELLES, J.M.; NORMAN, J.M. Instrument for indirect measurement of canopy architecture. Agronomy Journal, v.83, p.818-825, 1991.

$\overline{\text { Recebido em } 10 \text { de maio de } 2006 \text { e aprovado em } 18 \text { de outubro de } 2006}$ 